\title{
Crescimento, emprego e renda no Brasil: rumo ao pleno emprego produtivo
}

João Basilio Pereima* Ricardo Nascimento ${ }^{* *}$

Resumo: Com recordes positivos em relação às menores taxas de desemprego já registradas, e com um aumento real nos salários da população, a economia brasileira entra em um debate sobre a possível existência de uma situação de pleno emprego. $O$ presente artigo faz uma breve revisão sobre as teorias por trás da ideia do pleno emprego, relacionando mercado de trabalho, crescimento, inovação e progresso tecnológico na produção, bem como apresenta uma síntese de dados que mostram questões como a evolução demográfica, o grau de informalidade, a qualidade da mão de obra e seus rendimentos no Brasil. Defende-se que a condição de pleno emprego é real quando temos em mente a ideia do pleno emprego produtivo, mas que o mercado de trabalho brasileiro ainda precisa avançar em termos qualitativos para atingir um pleno emprego social.

Palavras-chave: Crescimento; Mercado de Trabalho; Emprego.

Classificação JEL: E24; J21; O1.

\footnotetext{
" Doutor em Desenvolvimento Econômico pela Universidade Federal do Paraná (UFPR). Professor adjunto do Departamento de Economia da UFPR e do Programa de Pós-Graduação em Desenvolvimento da UFPR. Vice-Chefe do Departamento de Economia e editor da Revista Economia \& Tecnologia (RET). Endereço eletrônico: joaobasilio@ ufpr.br.

** Graduando em Economia pela Universidade Federal do Paraná (UFPR). Supervisor técnico da Revista Economia \& Tecnologia (RET). Endereço eletrônico: ricardonascimento.ric@gmail.com.
} 


\section{Introdução}

A economia brasileira ingressou a partir de 2004 num ciclo de crescimento econômico o qual teve como uma das consequências aproximar a economia, pela primeira vez em sua história, de uma situação de pleno emprego. A taxa agregada de desocupação caiu para seu nível mais baixo da série histórica iniciada em 2002 , atingindo $4,7 \%$ em dezembro de 2011 , subindo um pouco para $5,8 \% \mathrm{em}$ maio de 2012, com uma população desocupada ${ }^{1}$ estimada em 1,13 e 1,41 milhões de pessoas nos respectivos meses, segundo dados do IBGE. Embora haja um contingente muito grande de população ainda não ab sorvido pela economia formal e vivendo em situação de pobreza, há também uma dificuldade crescente do setor produtivo em encontrar oferta de trabalho qualificado em diversos setores da economia. Até mesmo setores com baixa produtividade da mão de obra, como construção civil, não conseguem preencher a demanda, refletindo-se em aumentos salariais. Este fenômeno se repete em outros setores, especialmente com mão de obra qualificada. Uma tal proximidade do pleno emprego já está mudando as relações salariais que desde sempre foram altamente concentradoras de renda, com salário muito baixo, geradoras de altíssimas taxas de lucros, engendrando um regime de crescimento econômico puxado por lucros (profit-led). $\mathrm{O}$ aumento real de rendimentos do trabalho informal em 40\% desde 2003 é um sintoma de como o capitalismo brasileiro é viciado em altos lucros e possui uma grande margem para absorver aumentos de salários. E mais ainda, que este aumento de salários foi uma das bases de sustentação do crescimento recente, puxado pela demanda (wage-led).

Apesar da crise de 2008 e sua segunda fase recessiva de 2011/2012 mudar o cenário conjuntural brasileiro para baixo crescimento, estes dois episódios não encobrem uma mudança até certo ponto estrutural e de curso longo do mercado de trabalho que é a aproximação do pleno emprego. Se o Brasil voltar a crescer num ritmo superior a 3,0\% a.a. nos próximos anos, as restrições pelo lado do mercado de trabalho ficarão cada vez mais evidentes.

O rol de evidências positivas que favorecem a tese da proximidade do pleno emprego gira em torno, essencialmente: i) da redução sistemática da taxa geométrica de crescimento da população ${ }^{2}$; ii) da taxa média de crescimento do PIB nos últimos 10 anos de 3,76\% a.a.; iii) do aumento significativo da população ocupada nas regiões metropolitanas; iv) do aumento do rendimento médio efetivo do trabalhador formal e informal; e por fim v) na taxa de informalidade.

Em que pese as diferenças setoriais e regionais do mercado de trabalho, e o longo caminho que o país ainda precisa percorrer para criar uma economia

\footnotetext{
1 IBGE, Pesquisa Mensal do Emprego. Taxa de desocupação é calculada tomando-se pessoas de 10 anos ou mais de idade, desocupadas na semana de referência da pesquisa, em seis regiões metropolitanas do Brasil: Recife, Salvador, Belo Horizonte, Rio de Janeiro, São Paulo e Porto Alegre.

2 Em 2011, estimada em 0,86\% a.a., pelo IBGE.
} 
socialmente mais justa, são muitas as evidências de uma mudança no mercado de trabalho brasileiro, principalmente pela dificuldade de contratação de mão de obra na quantidade e qualidade desejada. O mercado de trabalho até então caracterizado por oferta ilimitada a salários muitos baixos começa a apresentar novas dinâmicas, exigindo mudança no regime de crescimento do país, o qual, até o momento, foi sustentado quase que exclusivamente por acumulação de capital e trabalho e pouca inovação.

Nas seções seguintes deste artigo revisamos alguns aspectos teóricos macroeconômicos sobre mercado de trabalho, emprego e crescimento, mostramos evidências descritivas de que o país ruma para o pleno emprego e as consequências que isto terá para o modelo de crescimento da economia.

\section{Emprego nas teorias econômicas}

A ciência econômica tem tratado o tema do emprego ou seu outro lado, o desemprego, com diferentes perspectivas, abordagens teóricas e métodos. Podemos agrupar o problema do emprego em três perspectivas distintas e complementares: a primeira envolve as teorias de crescimento e desenvolvimento econômico com uma visão de longo prazo, onde o emprego é analisado em conjunto com a ocorrência de mudança estrutural, com efeitos sobre o aumento ou deterioração da qualidade do emprego; a segunda perspectiva é a da teoria macroeconômica e de ciclos de negócios e envolve ajustes no mercado de trabalho e relações entre desemprego e inflação; por fim a terceira perspectiva envolve a teoria microeconômica do mercado de trabalho, a qual trata das condições de oferta e demanda de mão de obra e os mecanismos de seleção, contratos, barganhas, remuneração, qualificação etc. Enquanto as duas abordagens macroeconômicas tratam as mudanças e oscilações no mercado de trabalho a partir dos saldos líquidos de criação e destruição de emprego, a abordagem microeconômica dedica-se, entre outras coisas, a descrever separadamente o processo de criação, destruição e realocação do emprego.

\subsection{Desenvolvimento, crescimento e emprego}

O problema do emprego é tratado de diferentes maneiras nas teorias de crescimento e desenvolvimento econômico. No caso das teorias dualistas de desenvolvimento de Arthur Lewis (1954) e Harry e Todaro (1970), afirma-se que nos primeiros estágios de crescimento, uma economia predominantemente agrícola que começa a se industrializar conviverá com um longo período de crescimento com oferta ilimitada de mão de obra, devido a migração populacional do setor agrícola para o industrial. Enquanto isso permanecer, o salário médio do setor agrícola ou atrasado será determinado pelo nível de subsistência e o 
salário médio do setor industrializado será um pouco maior a ponto de atrair o trabalho do campo, mas não tão alto a ponto de comprometer as altas taxas de lucros que se observa no setor industrial. A economia convive, portanto, com uma alta taxa estrutural de desemprego e uma população dividida entre um setor de salários próximos ao nível de subsistência e um setor industrial com salários um pouco acima deste nível. Nesta fase do desenvolvimento econômico, a participação dos salários na renda é baixa, comparativamente a participação dos lucros. A mudança estrutural numa economia que se industrializa e absorve cada vez mais mão de obra é tal que no início, quando todos ou quase todos estão no campo (ou no setor atrasado), a desigualdade de renda é baixa. Todos são pobres. Na medida em que a migração entre os setores ocorre, a desigualdade aumenta até atingir um ponto de máximo a partir do qual começa a cair. Isto ocorrerá próximo ao ponto em que mais da metade da população estiver sendo empregada no setor industrial, produzindo um fenômeno que ficou conhecido como a curva em formato de "U-invertido", depois de descrito por Simon Kuznets (1955). Analisando a relação entre desigualdade e renda per capita, Kuznets encontrou evidências nos dados de que esta relação é não linear na forma de um U-invertido, quando se compara a variável desigualdade (eixo vertical) com a renda per capita (eixo horizontal). Espera-se que a desigualdade diminua quando um certo nível de rendimento médio é atingido e os processos de industrialização, democratização e o surgimento do estado de bem-estar permitirem distribuir os benefícios do rápido crescimento, aumentando a renda per capita de forma mais equitativa. Embora Kuznets não tenha tratado do mercado de trabalho, sua abordagem é compatível com a teoria dualista.

$\mathrm{Na}$ chamada teoria moderna do crescimento $^{3}$, o emprego aparece como um fator de produção numa função de produção que admite substituição de capital por trabalho e que apresenta retorno decrescente ao nível do fator e retornos constante de escala. Assumindo que as economias são competitivas com mercados completos, a teoria moderna do crescimento afirma que a remuneração dos fatores de produção capital e trabalho será determinada pelo produto marginal de cada um dos fatores. O salário, em termos unitários, será igual a produtividade da mão de obra e o retorno do capital será igual ao produto marginal do capital. Assim, numa economia primitiva, com baixa relação capitaltrabalho $(K / L)$, a escassez de capital faz com que o produto marginal do capital seja maior que o produto marginal do trabalho e a economia então passe a acumular capital numa velocidade maior que o aumento de trabalho. Com altas taxas de investimento em capital $(\Delta K=I=s Y)$, proporcionada por uma taxa de poupança $(s)$ relativamente elevada, em relação ao estoque de capital existente, a relação capital-trabalho cresce até atingir um valor de equilíbrio de longo

3 Cuja base são os modelos e métodos de Solow (1956), Swan(1956), Ramsey (1928), Cass (1965) e Koopmans (1965). 
prazo, quando então o estoque de capital estará crescendo a uma taxa igual ao crescimento da força de trabalho. Durante o período de transição, mesmo não havendo progresso tecnológico e aumento de produtividade, a renda per capita pode crescer porque a expansão do capital físico incorporará um contingente de trabalhadores que até então não participavam do processo produtivo, os quais terão um aumento de renda e porque a renda total estará crescendo numa velocidade maior que aumento populacional. Esta nova renda, comparada à renda de subsistência anterior, se traduz em maior nível de renda agregada e ao mesmo tempo em maior renda per capita.

No entanto, se certos limites estiverem presentes, especialmente os retornos decrescentes ao nível do fator capital e trabalho, o estoque de capital físico não poderá aumentar indefinidamente, nem mesmo a relação capitaltrabalho. A medida que o estoque de capital físico cresce numa velocidade maior que a força de trabalho, em algum ponto do tempo a economia convergirá para uma relação capital-trabalho limite, chamada de "estado estacionário" (steadystate). Neste ponto do tempo, a taxa de crescimento da renda per capita será zero. Isto se deve ao fato de que, a partir deste momento, a taxa de crescimento da renda agregada em nível será igual a taxa de crescimento do estoque de capital, que por sua vez será igual a taxa de crescimento da população em idade ativa. Formalmente, esta relação pode ser mais facilmente demonstrada se tomarmos uma função de produção genérica, por enquanto sem progresso tecnológico, representando-a como $Y(t)=F[K(t), L(t)]$, onde $Y(t)$ é o nível de renda agregada, $K(t)$ o estoque de capital e $L(t)$ a população em idade ativa, todos variando no tempo. Esta última atingirá o máximo quando a economia crescer o suficiente para absorver o total de mão de obra disponível na economia. A função de produção pode ser representada em termos de taxas percentuais de variação por $\dot{y} / y=\dot{K} / K-\dot{L} / L=g-n$, onde $\dot{y} / y$ é a taxa de crescimento da renda per capita.

Este resultadoé importante para as implicações que o mercado de trabalho tem sobre o crescimento econômico. $\mathrm{O}$ que a equação de crescimento da renda per capita mostra é que quando $K(t)$ e $L(t)$ atingirem sua relação $(K / L)$ limite então o crescimento da renda per capita será zero, pois ambos estarão variando na mesma velocidade. E mais ainda, se a taxa de crescimento populacional, ou população em idade ativa, for zero, então não haverá nem mesmo crescimento

\footnotetext{
4 Se tomarmos uma função de produção genérica $Y(t)=F[K(t), L(t)]$ e dividirmos por $L(t)$ com o objetivo de calcular a renda per capita $(y=Y / L)$ teremos: $\mathrm{y}(\mathrm{t})=\mathrm{F}\left[\frac{K(t)}{L(t)}, 1\right]$.

Se aplicarmos uma transformação logarítmica na equação da renda per capita teremos uma expressão linear: $\operatorname{Ln} y(t)$ $=L n K(t)-L n L(t)$ e, por fim, tomando a derivada desta equação, agora em logarítmos, em relação ao tempo $t$ temos as taxas de variação: $\frac{\frac{d y(t)}{d t}}{y(t)}=\frac{\frac{d K(t)}{d t}}{K(t)}-\frac{\frac{d L(t)}{d t}}{L(t)}$ ou simplesmente $\dot{y} / y=\dot{K} / K-\dot{L} / L$ ou $\dot{y} / y=g-n$.
} 
da renda (ou do PIB) em nível, a não ser que haja inovação ou aumento de produtividade $^{5}$. O processo de acumulação de capital chegará ao seu fim e as sociedades estagnarão. Aumentos na taxa de poupança e investimento poderão temporariamente deslocar este limite para um nível de renda maior, mas isso não poderá acontecer sempre. Há limites para expandir a taxa de poupança e investimento e novamente o ponto de estagnação é alcançado. Esta relação capital-trabalho de equilíbrio pode ser entendida como sendo uma situação de pleno-emprego, na teoria moderna do crescimento.

Quando uma economia se aproxima da sua relação capital-trabalho de equilíbrio, ou do pleno emprego, a única maneira de expandir a renda per capita é através da inovação, pondo em marcha então o segundo estágio ou processo de expansão da renda per capita. A inovação pode afetar a produção e a renda per capita de formas tão diversas como aumento de produtividade, novos processos produtivos, novas matérias-primas ou criação de novos produtos. Este último implica em novos bens na cesta do consumidor realimentando a demanda agregada. Os efeitos positivos da inovação, qualquer que seja ela, são contrabalançados com os efeitos destrutivos sobre o capital antigo e sobre a mão de obra que o acompanha. Para começar a agir, a inovação, como de fato ocorre na prática, nem mesmo espera que a sociedade atinja seu estadoestacionário ou a relação $K / L$ de equilíbrio, a qual configura uma situação de pleno emprego como dito. A concorrência schumpeteriana, motivada pela possibilidade de apropriação de lucros de monopólio obtidos pela vantagem em inovar, põe em movimento um processo criativo-destrutivo mesmo que a economia esteja abaixo de pleno emprego, o que torna o problema do emprego uma questão mais complexa, pois não há garantias de que o efeito criativo das inovações sobre o mercado de trabalho seja maior que o efeito destrutivo, um problema que a abordagem de fluxos do mercado de trabalho tem tentado resolver (Davis; Haltiwanger, 1992). Além disto, discernir estatisticamente e de modo suficientemente claro a criação, destruição e realocação de mão de obra que decorre da introdução de inovação ou da oscilação de ciclos de negócios não é uma tarefa trivial e permanece um problema a ser resolvido.

\subsection{Mercado de trabalho, ciclos de negócios e inflação}

Na abordagem macroeconômica de curto prazo, o problema do emprego aparece ora como uma consequência das flutuações do produto e renda e ora uma das causas da inflação por aumentos de salários nos casos de expansão da demanda de trabalho acima da oferta.

5 Veremos na próxima seção que a transição demográfica no Brasil é tal que a taxa de crescimento da população em idade ativa (PIA) será igual a zero em 2020, e a da população como um todo será zero em algum ponto entre 2035 e 2040, segundo estudos do IBGE. 
Durante um ciclo de negócios, expansionista ou contracionista, o mercado de trabalho sofre ajustes mais rapidamente que outras formas de fatores. Durante transições ao longo de um ciclo as empresas aumentam ou diminuem a quantidade de trabalho por meio de horas extras, abertura ou fechamento de turnos e contratação ou demissão, de forma que variações na demanda agregada podem impactar com relativa facilidade a demanda de mão de obra. O mercado de trabalho será considerado mais ou menos flexível a depender de como ele está organizado institucionalmente e responde aos ciclos. Este grau de flexibilidade é o que distingue duas correntes teóricas importantes na macroeconomia: a abordagem clássica (Pigou, 1933) e novo-clássica (Sargent, 1973) de um lado; e a abordagem keynesiana de outro. Grosso modo, a essência que distingue estas duas escolas é o grau de rigidez dos preços e salários admitidos por cada uma. Nenhuma rigidez no caso da primeira, muita rigidez no caso da segunda. O grau de rigidez por sua vez determinará as condições de equilíbrio no mercado de trabalho e é um importante determinante do nível de emprego a cada instante.

No caso da flexibilidade plena, o mercado de trabalho restaura o equilíbrio e o pleno emprego com rapidez, ao passo que a rigidez, especialmente de salários nominais, pode conduzir a equilíbrios com desemprego. No mundo flex, digamos assim, tanto o mercado de trabalho quanto o mercado de bens são suficientemente flexíveis para que o salário nominal $(W)$ e o preço dos bens e serviços $(P)$ se ajustem de tal forma que o salário real e o nível de emprego sejam mantidos constantes, implicando em pleno emprego automático, permanente. Quando ocorre um aumento de demanda de bens e serviços, por exemplo, dois ajustes ocorrem simultaneamente. Para atender a demanda de bens e serviços as empresas aumentam a produção e a demanda por mão de obra. Os salários nominais tendem a aumentar por causa disto, pois são flexíveis, e isto atrairia mais oferta de mão de obra (primeiro ajuste). Mas ao mesmo tempo, dado o retorno decrescente do trabalho para um dado nível do fator capital constante no curto prazo, o produto marginal do trabalho diminui. Isto implica em dizer que essa nova demanda de trabalho só seria viável para a empresa se ela oferecesse um salário nominal e real menor, o que não é factível, pois a demanda de mão de obra é maior. Para equilibrar seus lucros as empresas então aumentam preços dos bens e serviços em conjunto com o aumento do salário nominal (segundo ajuste). O salário nominal maior num primeiro momento tenderia a aumentar a oferta de trabalho, mas o aumento de preços garante que o salário real $(W / P)$ retorne rapidamente ao seu nível de equilíbrio restabelecendo o equilíbrio no nível de pleno emprego.

O mecanismo flex funciona também no caso de uma queda da produção. A correlata queda na demanda de mão de obra que se segue reduz o salário nominal e com isso a própria oferta de mão de obra. Como muitos trabalhadores 
não ofertam mão de obra com salário nominal e real mais baixo, os clássicos afirmam que o mercado de trabalho estaria ainda em equilíbrio, pois de fato não há oferta. Ninguém quer trabalhar. No entanto, a fim de tentar estimular suas vendas e mobilizar o capital ocioso, as firmas baixam preços de bens e serviços. $\mathrm{O}$ aumento no consumo que se segue permite que a empresa volte a contratar. A queda em $W$ e $P$ faz com que o salário real $W / P$ volte ao nível anterior, e novamente a quantidade de mão de obra retorna ao nível de pleno emprego.

Nos dois casos, de aumento e queda de demanda, o ajuste do mercado de bens e do mercado de trabalho, segundo a explicação flex, ocorre essencialmente via preços e não via quantidades. Os choques são rapidamente dissipados pelo sistema de preços de tal forma que o mercado de trabalho retorna sempre, e rapidamente, ao equilíbrio de pleno emprego em termos quantitativos. O desemprego, quando a população ocupada é menor que a população em idade ativa, seria então resultado voluntário, gerado pelos trabalhadores que consideram sua utilidade de lazer mais compensadora do que o trabalho por baixo salário real. O que restar de desemprego na economia será devido apenas a ajustes e fricções no mercado de trabalho.

Esta noção de ajuste automático da oferta de mão de obra com base na flexibilidade dos salários nominais e preços, de forma a restaurar o pleno emprego e os salários reais $(W / \mathrm{P})$, foi questionada a muito tempo por Keynes (1936, p. 45) quando afirmou que "isso não é exato, pois, se a oferta de trabalho não for uma função dos salários reais como sua única variável, seu argumento se desmorona por completo, deixando indeterminada a questão de qual será o nível efetivo de emprego". O que de fato ocorre, segundo Keynes, é que nem os salários nominais são suficientemente flexíveis para restabelecer o pleno emprego, nem a quantidade trabalho de equilíbrio é uma função apenas do salário real. No que se refere ao salário nominal, este pode variar, é claro, mas num certo intervalo de tempo, ao longo da vigência do contrato, o salário nominal está dado, de forma que mesmo um aumento de preço que faça o salário real diminuir, não diminuirá a oferta de trabalho, pois não é razoável supor que os trabalhadores irão abandonar seu trabalho toda vez que haja uma elevação no preço dos bens-salário (Keynes, 1936, p. 52). E no que se refere a quantidade de trabalho de equilíbrio, a função de oferta de mão de obra com base no salário nominal estabelece apenas a quantidade máxima ou pretendida de unidades de trabalho a serem oferecidas pelos trabalhadores. A quantidade exata ou efetiva dependerá dos efeitos das variações de preços sobre a demanda efetiva. Somente depois de conhecida a demanda efetiva é que a taxa de desemprego será definida. Um aumento de preço, dado um salário nominal, embora reduza o salário real, não afetará a oferta de mão de obra. Mas terá um efeito negativo sobre a demanda efetiva a depender da propensão a consumir da sociedade (dos trabalhadores) 
e um efeito positivo caso a maior taxa de lucro oriunda do aumento de preços se converta em mais investimentos, e cujo timing se concretiza num período de tempo maior do que o desequilíbrio no mercado de trabalho. Em síntese, é possível haver um equilíbrio com desemprego, abaixo da situação de pleno emprego que se observaria caso tudo fosse flexível.

Os mecanismos de correção de desequilíbrios no mercado de trabalho, assumindo certo grau de rigidez, são tais que há de fato uma relação entre variação dos salários e taxa de desemprego, produzindo a chamada curva de Phillips (1958), a qual estabelece uma curva negativamente inclinada entre salários nominais e taxa de desemprego. A curva de Phillips, uma constatação empírica de vários economistas, é mesmo assim objeto de controvérsia. A relação entre salários e mais recentemente inflação e desemprego é enfraquecida se for incorporada um termo expectacional (Phelps, 1967), e pode até mesmo desaparecer se os agentes formarem expectativas racionais, do tipo forward looking (Sargent, 1973).

A análise do pleno emprego, portanto, é muito sensível ao horizonte de tempo e ao tipo de mudança, se estrutural ou conjuntural, que se tenha em mente. Na análise de curto prazo, sobressaem-se flutuações do emprego ao longo do ciclo econômico, no qual as relações entre taxa de desemprego e inflação são o principal problema. Além disso, o nível de emprego flutua em torno de um estoque de capital e população assumido como constante no curto prazo, de forma que mudanças importantes, principalmente decorrentes da acumulação de capital e alterações demográficas, não estão contempladas.

Quando afirmamos que o mercado de trabalho brasileiro caminha rumo a uma situação de pleno emprego é porque temos em mente um conjunto de transformações que está além dos desequilíbrios de curto prazo e decorre do processo conjunto de crescimento econômico com transição demográfica. Evidentemente, ciclos econômicos são importantes e podem acelerar ou retardar a marcha para o pleno emprego. Se o ciclo for suficientemente agudo, como está sendo na Europa e EUA durante a crise financeira iniciada em 2007, pode até mesmo produzir alta taxa de desemprego. Pior ainda, se esta taxa persistir por muito tempo ela pode evoluir, por histerese (Cahuc, 2004, p. 476 e seguintes), para uma situação de desemprego estrutural elevado com graves consequências sociais. A economia se adapta, destruindo postos de trabalho para sempre, e a sociedade passa a conviver durante um período muito longo de tempo com uma alta taxa de desemprego crônica, que não existia antes. 


\section{Algumas evidências empíricas sobre população, emprego e renda}

As transformações no mercado de trabalho na economia brasileira na última década resultam de uma combinação de ciclo de crescimento econômico baseado em acumulação de capital e trabalho iniciado em 2004 com significativa e rápida transição demográfica. Estas mudanças poderão ser mais bem compreendidas se levarmos em conta a tendência de crescimento da economia, mais que os ciclos. Evidentemente, o atual período de transição carrega consigo heranças passadas de graves desequilíbrios, como heterogeneidade regional e setorial e qualidade do emprego e do trabalhador. No entanto, a visão estática destas diferenças pode obscurecer as transformações estruturais em curso.

A fim de capturar mudanças estruturais, apresentamos nesta seção uma série de indicadores econômicos e demográficos que afetam a dinâmica do mercado de trabalho. $\mathrm{O}$ calculo da taxa de desemprego, ou sua contrapartida, do pleno emprego, requer alguns cuidados metodológicos, pois a medida de desemprego pode variar conforme o conceito utilizado. Mas, em geral, todas as formas de cálculo de desemprego apontam significativa queda, especialmente desde 2004. Também deve-se levar em conta a diferença entre o setor formal e a imensa população subempregada no setor informal. Comumente assumimos que é possível haver pleno emprego produtivo, quando as empresas não conseguem contratar porque não existe mão de obra na quantidade e qualidade desejada, e ao mesmo tempo haver desemprego social, quando um grande contingente de pessoas não consegue acessar o mercado de trabalho e ofertar mão de obra por limitações de conhecimento e destreza.

\subsection{Demografia e emprego}

Uma das grandes transformações recentes da sociedade brasileira, com efeitos diversos sobre a qualidade de vida da população e em especial sobre o mercado de trabalho, é a queda intensa da taxa de crescimento populacional. A população brasileira continua a crescer, mas em ritmo mais lento: a taxa de fecundidade total em 2010 foi de 1,8 filhos por mulher, enquanto na década de 60 era de quase 6 filhos, segundo o IBGE. Se o número de pessoas em idade de trabalho cresce em relação à população, a produção dela advinda pode ser maior do que a sua necessidade, gerando maior poupança e consequente maior investimento, o que por sua vez tornaria sustentado o crescimento econômico acelerado durante algum tempo (Alves; Vasconcelos; Carvalho, 2010). Neste tempo a oferta se expande e encontra um escoamento natural devido ao aumento da demanda oriundo da absorção de trabalho e geração de renda. Tal 
conformação populacional é conhecida pela literatura como bônus demográfico, e sua existência no Brasil vem sendo amplamente discutida. Para realmente ser um bônus, no entanto, tal condição precisa ser devidamente explorada. E uma das condições necessárias é a realização de investimentos em educação, como forma de qualificar a mão de obra num ambiente propenso à inovação, como é a sociedade moderna.

Como pode ser visto na Tabela 1, a população em idade ativa cresceu, no período analisado, num ritmo sempre superior ao da população, caracterizando aqui a geração do bônus da transição demográfica. Esse crescimento, no entanto, vem se desacelerando. Enquanto as taxas de crescimento populacional e da PIA estão diminuindo ao longo do tempo, o número de pessoal ocupado está aumentando e a taxa de desemprego diminuindo. Ao longo de 20 anos a variação acumulada da população é $28,6 \%$, enquanto que do pessoal ocupado foi de $48,9 \%$ e do PIB 86,3\%. É também significativo o fato de que nos últimos 20 anos o mercado de trabalho consegui incorporar todo o aumento da população em idade ativa. A taxa de crescimento acumulada da PIA foi de 46,8\%. Levando em conta que no período houve também aumento de produtividade, pois o PIB aumentou $86,3 \%$, não pode passar despercebido o fato de que o mercado de trabalho no Brasil, senão eliminou seus problemas históricos, deu significativos passos na absorção de mão de obra.

Tabela 1 - População, Emprego e Crescimento no Brasil

\begin{tabular}{|c|c|c|c|c|c|c|c|c|}
\hline \multirow{2}{*}{ Ano } & Pop. & $\mathbf{P I A}^{1}$ & $\begin{array}{l}\text { Pessoall } \\
\text { ocup. }\end{array}$ & Pop. & PIA & $\begin{array}{l}\text { Pessoal } \\
\text { ocup. }\end{array}$ & \multirow{2}{*}{ desemp. $^{\text {Taxa }}$} & \multirow{2}{*}{ (\% PIB } \\
\hline & \multicolumn{3}{|c|}{$(\Delta \%$ a.a. $)$} & \multicolumn{3}{|c|}{ Milhares } & & \\
\hline 1992 & 1,64 & 2,43 & & 151.547 & 113.633 & 15.269 & - & $-0,47$ \\
\hline 1993 & 1,61 & 2,39 & 0,56 & 153.986 & 116.399 & 15.354 & - & 4,67 \\
\hline 1994 & 1,59 & 2,37 & 3,54 & 156.431 & 119.178 & 15.897 & - & 5,33 \\
\hline 1995 & 1,56 & 2,29 & 1,99 & 158.875 & 122.003 & 16.214 & - & 4,42 \\
\hline 1996 & 1,54 & 2,15 & 1,82 & 161.323 & 124.796 & 16.509 & - & 2,15 \\
\hline 1997 & 1,52 & 2,07 & $-0,57$ & 163.780 & 127.483 & 16.415 & - & 3,38 \\
\hline 1998 & 1,51 & 1,99 & $-0,04$ & 166.252 & 130.120 & 16.409 & - & 0,04 \\
\hline 1999 & 1,50 & 1,92 & 1,07 & 168.754 & 132.709 & 16.585 & - & 0,25 \\
\hline 2000 & 1,50 & 1,81 & 4,42 & 171.280 & 135.253 & 17.318 & - & 4,31 \\
\hline 2001 & 1,48 & 1,71 & 0,65 & 173.808 & 137.706 & 17.430 & - & 1,31 \\
\hline 2002 & 1,44 & 1,64 & 4,11 & 176.304 & 140.062 & 18.147 & 10,5 & 2,66 \\
\hline 2003 & 1,38 & 1,61 & 4,39 & 178.741 & 142.365 & 18.944 & 10,9 & 1,15 \\
\hline 2004 & 1,32 & 1,58 & 3,07 & 181.106 & 144.651 & 19.526 & 9,6 & 5,71 \\
\hline 2005 & 1,26 & 1,55 & 2,06 & 183.383 & 146.938 & 19.928 & 8,3 & 3,16 \\
\hline 2006 & 1,19 & 1,53 & 2,18 & 185.564 & 149.221 & 20.362 & 8,4 & 3,96 \\
\hline 2007 & 1,12 & 1,51 & 2,55 & 187.642 & 151.506 & 20.882 & 7,4 & 6,09 \\
\hline 2008 & 1,05 & 1,50 & 2,99 & 189.613 & 153.797 & 21.507 & 6,8 & 5,17 \\
\hline 2009 & 0,99 & 1,49 & 1,43 & 191.481 & 156.099 & 21.815 & 6,8 & $-0,33$ \\
\hline 2010 & 0,93 & 1,48 & 2,91 & 193.253 & 158.427 & 22.450 & 5,3 & 7,53 \\
\hline 2011 & 0,87 & 1,46 & 1,27 & 194.933 & 160.776 & 22.734 & 4,7 & 2,73 \\
\hline Acum & - & - & - & $28,6 \%$ & $46,8 \%$ & $48,9 \%$ & - & $86,3 \%$ \\
\hline
\end{tabular}

Fonte: Elaborado a partir de dados do IBGE.

Nota: (1) População em Idade Ativa (PIA), pessoas com 10 anos ou mais de idade; (2) Pessoal Ocupado nas Regiões Metropolitanas; (3) Taxa de Desemprego verificado no mês de dezembro nas Regiões Metropolitanas (nova metodologia da PME/IBGE, implantada a partir de 2002). 
Além disto, a diferença entre aumento da população e pessoal ocupado claramente revela um movimento duradouro de crescimento do emprego bem acima do crescimento populacional impulsionado pelo crescimento do PIB. Se esta tendência permanecer por mais algum tempo, talvez bem menos do que uma década ou mesmo um lustro, o mercado de trabalho e o modelo de crescimento recente do Brasil, baseado em expansão da demanda, enfrentará novas restrições.

\subsection{Oferta e demanda de mão de obra}

A análise demográfica feita anteriormente mostra que a oferta de mão de obra vem se reduzindo no Brasil. O crescimento da economia, por sua vez, se não acompanhado paralelamente por aumento da produtividade, faz com que a demanda por mão de obra aumente. Segundo estudo do IPEA (2012c), a variação média anual da produtividade da economia brasileira entre 2000 e 2009 foi de apenas $0,9 \%$, ao passo que o pessoal ocupado nesse mesmo período (Tabela 1) apresentou crescimento acumulado de $31,3 \%$.

A demanda por mão de obra qualificada, contudo, vem aumentando. Em 2001, 55\% da população ocupada tinha no máximo 7 anos de estudo, enquanto a população com 11 anos ou mais de estudo representavam menos de $30 \%$ desse contingente. Já em 2009, mais de 43\% da população ocupada tinha ao menos 11 anos de estudo, sendo que aqueles com no máximo 7 anos de estudo eram cerca de 40\% (IBGE), como mostrado no Gráfico 1.

Gráfico 1 - Pessoas de 10 anos ou mais de idade ocupadas, por anos de estudo específicos (2011 -2009)

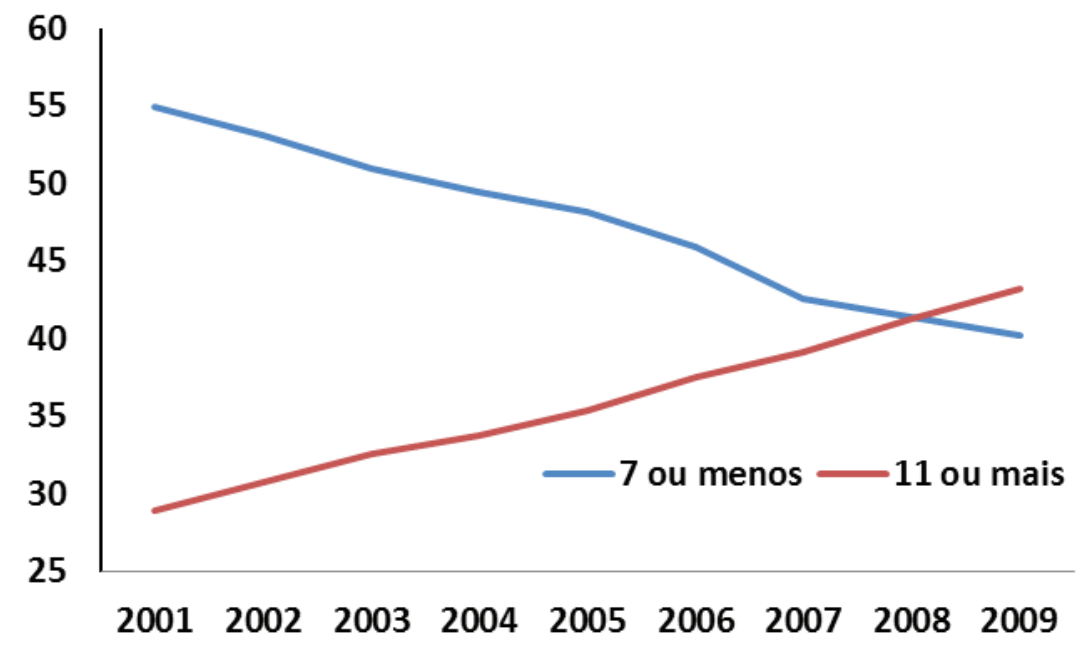

Fonte: Elaborado a partir de dados do IBGE.

Essa inversão da demanda por mão de obra qualificada indica que, por um lado, a própria população tornou-se mais escolarizada, e, por outro, que as 
empresas e demais contratantes buscam cada vez mais uma força de trabalho com qualificação e que a solução de problemas sociais como o desemprego social dependerá, doravante, muito mais de programas de educação do que simplesmente aumento da demanda de mão de obra decorrente de uma economia em expansão.

A oferta e a demanda de mão de obra podem apresentar variação muito grande quando analisadas setorialmente. Segundo comunicado do IPEA (2011b), para o ano de 2011, uma estimativa do saldo entre oferta e demanda de mão de obra no Brasil era de que haveria um excesso de cerca de 1 milhão de trabalhadores, conforme visto na Tabela 2. No entanto, quando a estimativa é desagregada por setores da economia, há um único setor com déficit: a indústria. Para 2011 a estimativa foi de que faltariam cerca de 34,5 mil trabalhadores qualificados para tal ocupação. Faltam, portanto, trabalhadores qualificados na quantidade demandada pelas indústrias, o que acarreta que há um pleno emprego produtivo, uma vez que todos aqueles que, devidamente qualificados, procurarem emprego nesse setor, aceitando receber o salário proposto, encontrarão emprego. Em geral estes dados enfraquecem o argumento do pleno emprego no Brasil. No entanto, eles precisam ser vistos dinamicamente, e não de forma estática. Se o país apresentar uma taxa média de crescimento econômico próxima de 3,5\% ou 4,0\% a.a. nos próximos cinco anos, este saldo poderá exaurir-se rapidamente, com mais setores sofrendo restrições que, por ora, atingem somente a indústria. Alguns setores, principalmente serviços em geral, são o refúgio da mão de obra não qualificada e apresentam o maior excedente de oferta.

Tabela 2 - Estimativa de saldo entre oferta e demanda de mão de obra em 2011 por grandes regiões geográficas

\begin{tabular}{l|r|r|rr|r|r}
\hline \multirow{2}{*}{\multicolumn{1}{c}{ Atividade }} & \multicolumn{7}{c}{ Região } \\
\cline { 2 - 7 } & \multicolumn{1}{c|}{ Norte } & Nordeste & Sudeste & Sul & $\begin{array}{c}\text { Centro- } \\
\text { Oeste }\end{array}$ & Brasil \\
\hline Administração pública & 10.576 & 22.364 & 15.521 & 12.581 & 10.744 & 71.786 \\
Agrícola & 1.454 & 46.227 & 78.257 & 11.638 & 12.946 & 150.522 \\
Alojamento e aliment. & -254 & 26.737 & 21.640 & 1.930 & 10.632 & 60.685 \\
Comércio e reparação & 22.319 & 81.245 & -82.997 & -660 & 30.377 & 50.283 \\
Construção & 15.287 & 16.612 & 9.518 & 9.743 & 16.176 & 67.336 \\
Educ, saúde, serv. soc. & 2.238 & 799 & 18.325 & 13.684 & 5.278 & 40.324 \\
Indústria & 10.811 & 25.849 & -15.013 & -51.590 & -4.556 & $\mathbf{- 3 4 . 4 9 9}$ \\
Outros serviços & 47.112 & 171.636 & 251.141 & 60.944 & 60.238 & 591.071 \\
Transp, armaz, comun & 1.605 & 13.577 & 32.140 & -2.860 & 6.807 & 51.270 \\
\hline Total & 111.149 & 405.046 & 328.534 & 55.410 & 148.640 & 1.048 .779 \\
\hline
\end{tabular}

Fonte: IPEA (2011b, p. 17).

\subsection{Trabalho formal e informal}

A partir de uma visão dualista do crescimento econômico, podemos interpretar o setor informal da economia como sendo o setor atrasado, de baixo salário, com remuneração próxima ao nível de subsistência, o qual funciona 
como "exército de reserva" de mão de obra barata. É sintoma dos estágios finais de um processo de crescimento e desenvolvimento econômico que tanto a informalidade caia quanto seus rendimentos aumentem a medida que a economia se encaminhe para este estágio mais evoluído.

Conforme pode ser visto no Gráfico 2, entre 2004 e 2012 a informalidade no Brasil se reduziu mais de 9 pontos percentuais, passando de $42,9 \%$ para $33,7 \%$ (na média até maio). Tal redução é, obviamente, louvável, mas o percentual de trabalhadores na informalidade é ainda grande: do total de quase 23 milhões de pessoas ocupadas em maio de 2012, cerca de 4 milhões não possuem carteira assinada (e outros 4 milhões trabalham por conta própria).

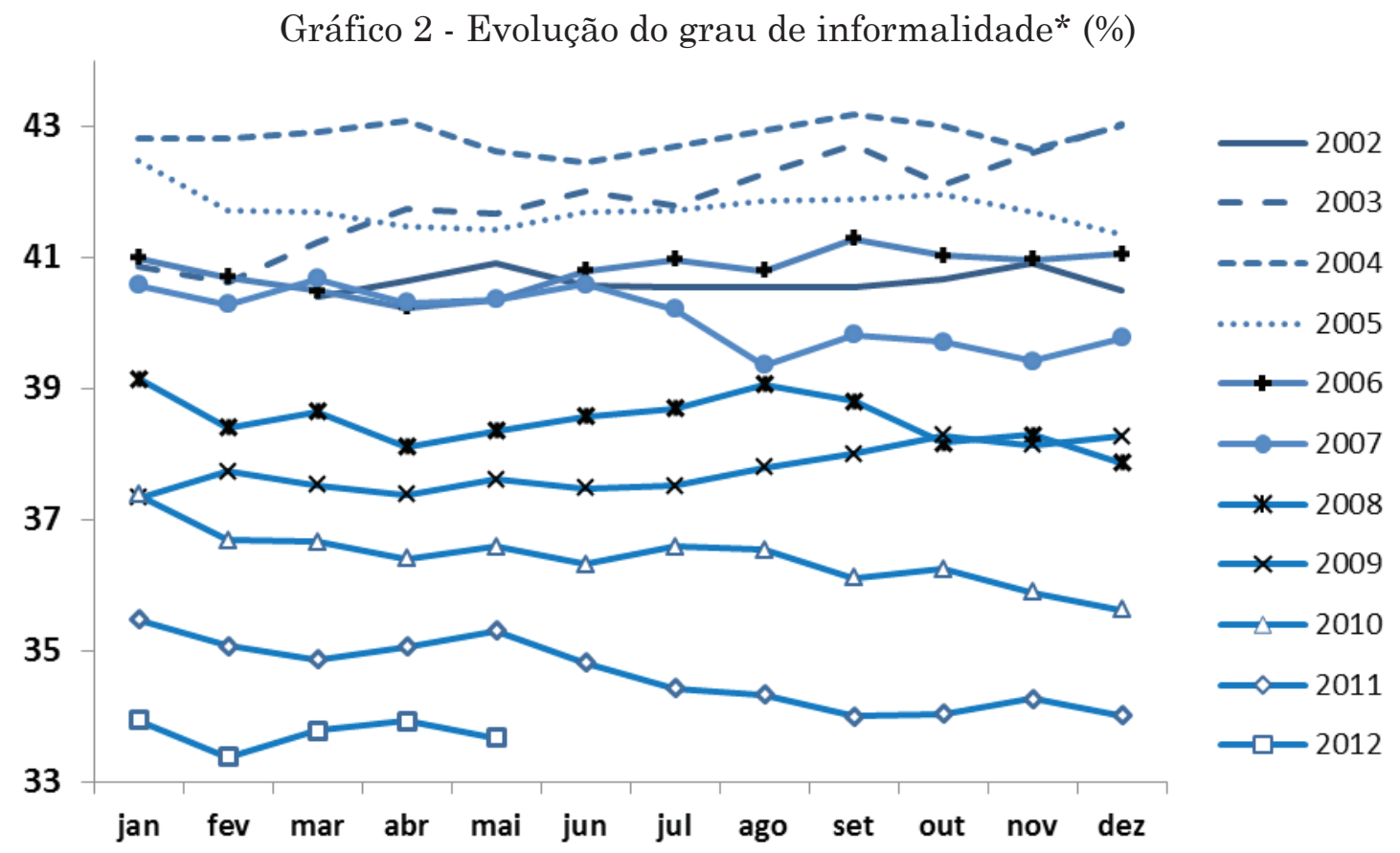

Nota: $\left(^{*}\right)$ Informalidade aqui considerada como a soma dos trabalhadores sem carteira assinada e por conta própria no total do pessoal ocupado.

Fonte: Elaborado a partir de dados da PME, IBGE.

No desagregado por ramos de atividade, percebemos que os trabalhos que exigem maior qualificação são justamente os com menor incidência de informalidade (Tabela 3): a administração pública possui, na média do período, $21 \%$ de seus trabalhadores na informalidade, e o conjunto educação, saúde e serviços sociais, 26\%. Já o setor com maior grau de informalidade é o agrícola, com $88 \%$ das pessoas ocupadas com esse ramo de atividade encontrando-se na informalidade. Outro setor com alto grau de pessoas sem carteira assinada é o da construção (71\%).

Dado interessante sobre a variação da informalidade no período é o da indústria: mais de $25 \%$ de redução, a maior dentre todos os ramos de atividade. Como observado na seção anterior, esse setor é o que possui o maior déficit entre 
oferta e demanda de mão de obra, e os dados da Tabela 3 revelam que os novos postos de trabalho criados são, sobretudo, formais.

Tabela 3 - Evolução do grau de informalidade por ramo de atividade (\%)

\begin{tabular}{l|r|c|c|c|c|c|c|c|c}
\hline \multirow{2}{*}{ Ramo de atividade } & \multicolumn{10}{|c|}{ Ano } & \multirow{2}{*}{ Var. } \\
\cline { 2 - 11 } & $\mathbf{2 0 0 2}$ & $\mathbf{2 0 0 3}$ & $\mathbf{2 0 0 4}$ & $\mathbf{2 0 0 5}$ & $\mathbf{2 0 0 6}$ & $\mathbf{2 0 0 7}$ & $\mathbf{2 0 0 8}$ & $\mathbf{2 0 0 9}$ & (2) \\
\hline Agrícola & 89,2 & 88,8 & 88,2 & 88,1 & 87,8 & 87,4 & 85,7 & 86,5 & $-3,1$ \\
Indústria & 62,7 & 62,8 & 57,0 & 59,2 & 55,6 & 53,7 & 49,2 & 46,9 & $\mathbf{- 2 5 , 2}$ \\
Construção & 74,1 & 75,4 & 73,0 & 72,6 & 71,6 & 71,0 & 66,2 & 65,4 & $-11,7$ \\
Comércio e reparação & 56,9 & 56,1 & 56,2 & 54,1 & 52,6 & 52,3 & 49,1 & 48,1 & $-15,5$ \\
Alojamento e alimente. & 62,4 & 62,6 & 61,8 & 59,6 & 57,8 & 57,0 & 56,3 & 55,6 & $-10,9$ \\
Transp, armaz, comun & 49,2 & 48,8 & 47,6 & 46,3 & 46,4 & 45,0 & 42,9 & 42,1 & $-14,5$ \\
Administração pública & 21,5 & 19,5 & 21,2 & 21,8 & 22,1 & 21,6 & 20,2 & 20,8 & $-3,5$ \\
Educ, saúde, serv. soc. & 26,6 & 26,0 & 26,2 & 28,3 & 27,0 & 26,9 & 25,7 & 25,3 & $-4,8$ \\
Outros serviços & 73,4 & 71,6 & 72,9 & 72,2 & 71,6 & 71,6 & 72,0 & 70,4 & $-4,1$ \\
\hline
\end{tabular}

Fonte: Elaborado a partir de dados das PNAD's.

\subsection{Rendimentos do trabalho}

Sinais de pleno emprego, ou de aproximação de tal realidade, também aparecem no comportamento dos salários, os quais têm aumentado em termos reais e de forma contínua na última década. Há na teoria econômica do trabalho duas abordagens para as relações entre crescimento, emprego e remuneração do trabalho. A abordagem dualista de Arthur Lewis (1954) e Harris e Todaro (1970) e a abordagem chamada job search ${ }^{6}$. A abordagem dualista opera no longo prazo e considera que enquanto o setor atrasado da economia for grande, a expansão econômica do setor desenvolvido poderá absorver mão de obra pagando um salário relativamente baixo, superior a ponto de atrair trabalhadores, mas próximo ao salário vigente no setor atrasado, ou do setor informal, suficiente para garantir altos lucros. Os salários são baixos e constantes, mesmo no setor desenvolvido. O problema da mobilidade de mão de obra entre os setores não é um entrave, pois as mudanças ocorrem num intervalo de tempo suficientemente grande para haver adaptação da mão de obra atrasada às exigências do setor desenvolvido. Os salários começariam a subir somente quando a oferta de mão de obra deixasse de ser ilimitada.

Por outro lado, a teoria baseada em mecanismo de mercado de trabalho do tipo job-search explora a dinâmica do mercado de trabalho como uma busca de melhores resultados em termos de trabalho, remuneração e lazer, onde interagem ofertantes (trabalhadores) e demandantes (firmas) em ambiente de incerteza. Segundo a abordagem job-search o mecanismo de busca e decisão dos agentes, trabalhadores e firmas, não é perfeito, e diferentes níveis de salários e desemprego podem emergir das relações de mercado, especialmente se o

6 Um bom resumo desta literatura encontra-se em Kiefer, Nicholas M. e Neumann, George R. (1989). 
mercado de trabalho for, de alguma forma, segmentado.

Em um trabalho publicado em 2011 intitulado "Expansão econômica e aumento da formalização das relações de trabalho: uma abordagem através das contratações", Corseuil e Foguel (2011), usando a teoria baseada em search models (mecanismos de buscas), fornecem evidências empíricas de que o mercado formal, não necessariamente o mercado de trabalho ligado ao setor desenvolvido da economia, mas apenas o setor formal indistintamente, durante um ciclo expansionista, se alimenta primeiro de trabalhadores oriundos do grupo de desempregados e somente numa segunda fase de trabalhadores oriundos do grupo de trabalhadores informais. A razão se deve ao fato de que trabalhadores desempregados possuem salário de reserva menor que os trabalhadores informais, os quais bem ou mal possuem alguma renda. Daí a preferência das empresas por desempregados ao invés de trabalhadores informais. Assim, espera-se que quando o estoque de mão de obra desempregada (a primeira a ser demanda) for suficientemente baixo a demanda de mão de obra atingirá o setor informal e os rendimentos e salários começarão aumentar ali. De fato, de acordo com o Boletim de Mercado de Trabalho do IPEA (2012a), as estatísticas do setor informal de trabalho no Brasil apontam para uma sistemática elevação dos rendimentos do setor informal, cujos rendimentos reais efetivos subiram $40 \%$ em termos reais, de $\mathrm{R} \$ 816,46$ em 2003 para $\mathrm{R} \$ 1.140,59$ em novembro de 2011 (IPEA, 2012a, tabela V. 4, p. A26). Ao mesmo tempo houve uma redução no índice de informalidade, de 58\% em 1999 (IPEA, 2012a, gráfico 7, p. 37) para menos de 35\% em 2011 (IPEA, 2012a, gráfico 6, p. 20). A elevação real dos rendimentos do trabalho desagrupados é mostrada no Gráfico 3, o qual mostra um aumento generalizado de rendimentos.

Gráfico 3 - Rendimento Médio Efetivo do Trabalhador (2002-2012)

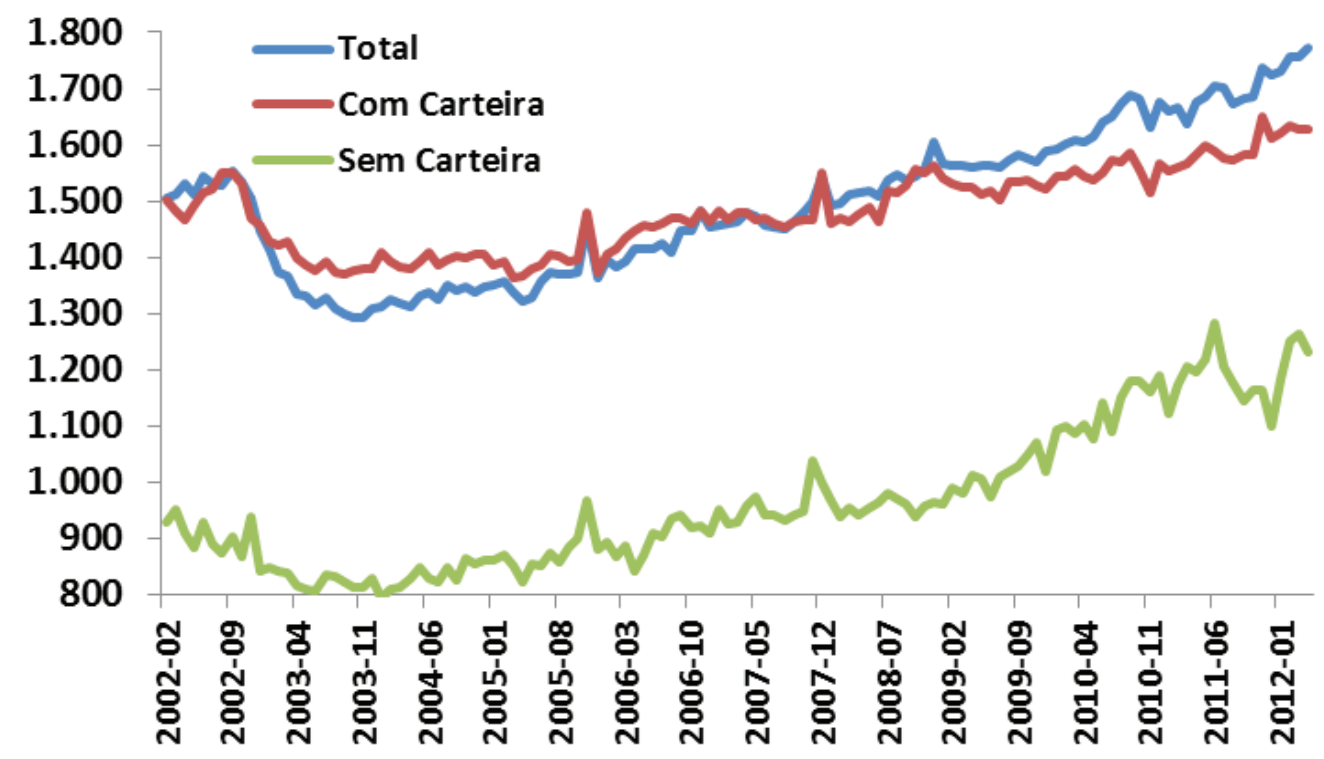

Fonte: Elaborado a partir dos dados da PME/IBGE. 
Esta tendência, consolidada nos últimos 10 anos, evidencia que as transformações no mundo do trabalho formal têm se transmitido ao trabalho informal, inclusive no que se refere à remuneração.

\section{Rumando para o pleno emprego}

Uma das críticas recorrentes para a hipótese do pleno emprego reside no fato de que o mercado de trabalho no país é marcado por alto nível de informalidade, baixos salários e empregos precários; de fato, existe atualmente exército de mão de obra disfarçado em formas diversas de subemprego, jornadas de trabalho parciais e executadas, em grande parte, em funções de serviços terceirizados. Por outro lado, reforçando a hipótese do pleno emprego, existe a escassez de mão de obra qualificada, o que faz persistir a baixa competitividade e fraca eficiência das empresas brasileiras. Além disto, como os dados apontam, tem havido sistemática queda da taxa de informalidade e um aumento generalizado dos rendimentos do trabalho.

A caracterização do pleno emprego não é uma tarefa trivial para a economia, e, por incrível que pareça, ainda não dispomos de um indicador suficientemente claro que indique que uma economia chegou ou não no pleno emprego. A taxa de desemprego, embora sirva a muitos propósitos, é a melhor aproximação, mas é uma informação incompleta. Em geral, afirmações do tipo "a economia está em pleno emprego" são feitas a partir de impressões gerais ou conclusões subjetivas, mais que objetivas. Comumente a constatação de pleno emprego é feita com utilização simultânea de vários indicadores do mercado de trabalho, como foi realizado na análise acima. A análise incluiu variação na população econômicamente ativa, pessoal ocupado, taxa de desemprego, taxa de informalidade, rendimentos. Todos indicando na mesma direção no Brasil e caso a economia continue crescendo num ritmo de 3,5 a 4,0\% a.a. nos próximos períodos é certo que o pleno emprego será alcançado.

O fato de afirmarmos que o país caminha para o pleno emprego, e de que ele pode estar perto, talvez a menos de um lustro, não significa negar as grandes disparidades existentes. Da mesma forma, uma análise estática, centrada numa radiografia desta realidade, não seria capaz de capturar as mudanças. A diferença aqui é metodológica. Nossa análise sobre o pleno emprego é de quem assiste a um filme e não de quem contempla uma fotografia. E há verdade, evidentemente, nas duas formas de registro dos fatos. A tendência do mercado de trabalho brasileiro dos últimos 10 anos, se permanecer por mais algum tempo, nos permite ser otimistas.

E se o pleno emprego é uma realidade próxima para a sociedade brasileira, como afirmamos que o seja, então o país ingressará numa nova fase de dinâmica 
econômica até o momento desconhecida tanto pelas empresas, quanto pelos trabalhadores e governo. Apenas sabemos o que é pleno emprego no Brasil por estudo da teoria econômica e sociológica; na prática, o país desconhece o que seja pleno emprego e a sociedade como um todo não está preparada para isso, muito menos as políticas públicas. Uma das grandes questões que serão levantadas doravante é o modelo de crescimento brasileiro, até o momento sustentado por acumulação de capital pura e simples, isto é, ampliação do estoque de capital físico e trabalho, e uma baixa contribuição do progresso tecnológico. No pleno emprego, a única forma de crescimento da renda per capita é via progresso tecnológico. E a política educacional e tecnológica do país neste ponto, comparativamente, está não apenas atrás do resto do mundo, como está muito aquém das novas realidades que se aproximam com velocidade. Nestes aspectos, especialmente o educacional, o país está atrasado em relação a si mesmo. Neste novo cenário, políticas macroeconômicas tradicionais têm pouco a oferecer, senão garantir estabilidade de preços, câmbio e do sistema financeiro.

\section{Referências}

Alves, J. E. D.; Vasconcelos, D. de S.; Carvalho, A. A. de. (2010). "Estrutura etária, bônus demográfico e população economicamente ativa no Brasil: cenários de longo prazo e suas implicações para o mercado de trabalho", Textos para Discussão CEPAL - IPEA n. 10, Brasilia.

Arbache, J. (2011). "Transformação demográfica e competitividade internacional da economia brasileira", Revista do BNDES 36: 365-392.

Ashenfelter, O. C.; Card, D. (1999). Handbook of labor economics, vol. 3C, NorthHolland.

Cahuc, P.; Zylberberg, A. (2004). Labor Economics. Cambridge: MIT Press.

Cass, D. (1965). "Optimum growth in an aggregative model of capital acumulation", Review of Economic Studies 32: 233-240.

Corseuil, C. H. L.; Foguel, M. N. (2011). "Expansão econômica e aumento da formalização das relações de trabalho: uma abordagem através das contratações", Texto para Discussão IPEA n. 1571, Rio de Janeiro.

Davis, Steven; Haltiwanger, John C. (1992). "Gross job creation, gross job destruction and employment reallocation”. Quarterly Journal of Economics 107(3): 819-63.

Harris, J. R.; Todaro, M. P. (1970). "Migration, unemployment and development: a two-sector analysis". American Economic Review 60: 126-142.

IPEA (2011a). "Características da formalização do mercado de trabalho brasileiro entre 2001 e 2009”. Comunicados do IPEA n. 88, Brasília.

IPEA (2011b). "Emprego e oferta qualificada de mão de obra no Brasil: projeções para 2011”. Comunicados do IPEA n. 89, Brasília. 
IPEA (2012a). Mercado de Trabalho: Conjuntura e Análise. n. 50, ano 17. IPEA e Ministério do Trabalho e Emprego, Brasília.

IPEA (2012b). Mercado de Trabalho: Conjuntura e Análise. n. 51, ano 17. IPEA e Ministério do Trabalho e Emprego, Brasília.

IPEA (2012c). "Produtividade no Brasil nos anos 2000-2009: análise das Contas Nacionais”. Comunicados do IPEA n. 133, Brasília.

Kiefer, Nicholas M.; Neumann, George R. (1989), Search models and applied labor economics. Cambridge: Cambridge University Press.

Koopmans, T. C. (1965). "On the concept of optimal economic growth". In Econometric Approach of Development Planning. Amsterdã: North-Holland.

Kuznets, Simon. (1955). "Economic growth and income inequality". American Economic Review 45: 1-28.

Lewis, Arthur. (1954). "Economic development with unlimited supplies of labour", The Manchester School 22(2): 139-191.

Phelps, Edmund S. (1967). "Phillips curve, expectations of inflation and optimal unemployment over time", Economica 34(135): 254-281,

Phillips, Arthur W. (1958). "The relation between unemployment and the rate of change of money wage rates in the United Kingdom, 1861-1957”, Economica, New Series 25(100): 283-299.

Pigou, A. C. (1933). Theory of Unemployment. London: Macmillan.

Ramsey, F. P. (1928). "A mathematical theory of saving”. Economic Journal 38(152): 543-559.

Sargent, T. J.; Fand, D.; Goldfeld, S. (1973). "Rational expectations, the real rate of interest, and the natural rate of unemployment". Brookings Papers on Economic Activity 2: 429-480.

Solow, R. M. (1956). "A contribution to the theory of growth". Quarterly Journal of Economics 70: 65-94.

Swan, T. W. (1956). "Economic growth and capital accumulation". The Economic Record 32: 334-361. 
